\title{
INFLUENCE OF EMOTIONAL INTELLIGENCE ON EMOTIONAL DISSONANCE AND INNOVATIVE WORK BEHAVIOR \\ Irfan Ullah Khan ${ }^{1 *}$, Muhammad Idris ${ }^{2}$, Sumaira Noreen ${ }^{3}$
}

${ }^{1 *}$ Department of Public Administration, Gomal University, Dera Ismail Khan, Pakistan; ${ }^{2}$ Department of Education, Abdul Wali Khan University, Mardan, Pakistan; ${ }^{3}$ Assistant Professor, Lahore College for Women University, Lahore, Pakistan. Email: ${ }^{1 *}$ irfanullah@gu.edu, ${ }^{2}$ midrees@awkum.edu.pk, ${ }^{3}$ sumnoreen2@yahoo.com Article History: Received on $5^{\text {th }}$ May 2021, Revised on $18^{\text {th }}$ May 2021, Published on $19^{\text {th }}$ May 2021

\begin{abstract}
Purpose of the study: This study aims to examine the effect of emotional intelligence on emotional dissonance and innovative work behavior by collecting data from the employees working in higher education institutions of KP, Pakistan.
\end{abstract}

Methodology: The study is cross-sectional which ensured a methodological approached to analyze the data to chase the answers to research questions by applying statistical procedures to conclude the study systematically.

Main findings: The results are significant which offer sufficient information in concluding the study by offering recommendations to policymakers and management of higher education institutions along with some suggestions to future researchers.

Application of the study: The results of this study might be helpful for the management of higher education institutions in revisiting their policies regarding the effective implementation of different measured concerning the research issues under consideration to provide a better solution in a tailor-made format.

Novelty/ Originality of the study: The study is significant in providing new findings, new knowledge, and new techniques about existing realities to the existing database of knowledge about the application of emotional intelligence, emotional dissonance, and innovative work behavior in higher educational institutions.

Keywords: Emotional Intelligence, Emotional Dissonance, Innovative Work Behavior, Higher Education Institutions, Pakistan.

\section{INTRODUCTION}

In the contemporary era, the management and supervision of emotions have become dynamic issues for organizations in attaining their desired standards. The workforces' emotions at workplaces are critical for the organizations in balancing their work attitude and work tasks. In this connection, in service organizations, the emotions of workforces cannot be ignored (Basch, Fisher, Ashkanasy, Härtel \& Zerbe, 2000). Consequently, the emotionally balanced workforces are dynamic forces for the organizations in achieving their long-term strategic objectives (Çakar \& Yasemin, 2004). Thus, emotional intelligence is an important phenomenon of organizations wherein the emotions and behaviors of the workforces are managed effectively to inspire them toward organisational survival and prolonged development (Cote \& Miners, 2006). Emotional intelligence leads the workforces towards innovative and creative behavior at the workplace thus inspired them to attain their assigned tasks effectively (Naeem, Saif \& Khalil, 2008). Hence, the innovative work behavior is critical for workforces for their readiness towards the realization of organizational tasks and objectives while the emotional dissonance is the ultimate disagreement towards the organizational strategic tasks.

Emotional dissonance is the psychological dissension caused by certain differences in interests overwhelmed by conflicts between the employees and employer. The conflict results in meager efforts and decreased performance as it is undesirably linked with various employees and organizational outcomes like emotional intelligence, innovative behavior, and elevated performance (Mishra \& Bhatnagar, 2010). Emotional dissonance denotes the structural inconsistency between the actual emotions and anticipated emotions that are required by the organization to accomplish the organizational tasks (Cheung \& Tang, 2012). It is related to the incongruity between established and authentic behavior leading to certain emotional circumstances (emotional stress \& exhaustion) while performing organizational tasks (Kenworthy, Fay, Frame \& Petree, 2014). The related discrepancies in the employees and organizational interests lead both towards lower performances and achievements as the suppression of factual feelings and emotions has unfavorable effects on employees' well-being and organizational health and thus undesirably affects creativity and innovation in the organizations.

The workforces' innovative behavior is critical in influencing their attitude toward particular tasks which inspires them to use innovative techniques to complete the assigned tasks. The innovative work behavior is the measuring factor for tracking the creativity, performance, and success of organizations and thus vital to facilitate the organizational climate for making suitable decisions (Jafri, Dem \& Choden, 2016). In this connection, the innovative work behavior is defined as intentional formation, overview, and submission of innovative ideas within the work role in a particular organization to advantage the 
role performance to achieve the desired objectives (Afsar, Cheema \& Saeed, 2018). Emotional intelligence and innovative behavior are critical in determining organizational tasks perceptively and inventively (Andrabi \& Rainayee, 2020). Conversely, emotional dissonance is the employees' disagreement toward organizational tasks due to emotional fatigue and undesirable policies and actions towards the workforces (Alam, Yifei, Raza \& Khan, 2020). In this regard, the role of emotional intelligence in determining emotional dissonance and innovative work behavior is the main theme of the present study.

\section{Problem Statement}

The problem addressed in this article is related to the role of emotional intelligence in determining emotional dissonance and innovative work behavior. Innovative work behavior and emotional intelligence are important phenomena for organizations that affect organizational development positively however, emotional dissonance is thus expected to affect the emotional intelligence and innovative work behavior undesirable. In this connection, this study aimed to examine the positivity and negativity of emotional intelligence with emotional dissonance and innovative work behavior.

\section{Objectives of Study}

$\checkmark$ To examine the association (correlation) between emotional intelligence, emotional dissonance, and innovative work behavior (in line with hypothesis \# 1).

$\checkmark$ To examine the impact (regression) of emotional intelligence on the emotional dissonance of the workforces (in line with hypothesis \# 2).

$\checkmark$ To examine the impact (regression) of emotional intelligence on innovative work behavior (in line with hypothesis \# 3).

\section{LITERATURE REVIEW}

For sustainable development, emotional intelligence is an imperative phenomenon that denotes the ability of the organizations to measure and manage the emotions of workforces to inspire them to use their abilities with positive thinking and innovative behavior to attain assigned tasks leading to higher achievements (Brackett, Mayer \& Warner, 2004). Emotional intelligence is the amalgamation of different components likewise the self-regulation, self-awareness, empathy, and motivation that when combined leads to emotive balance and culminates in strong emotional and intellectual abilities (Mayer, Salovey \& Caruso, 2008). Emotional intelligence affects the innovative behavior and performance of the workforces in diverse manners at different levels in the organizations which further significantly influences strategic decision making (Hasan \& Orhan, 2012). Thus, emotional intelligence has a direct influence on the innovative work behavior as the emotionally balanced workforces are likely to show better performance, higher commitment, and greater outcomes over innovative methods and practices as compared to those who have emotional disagreements.

Emotional intelligence not only helps in inspiring innovative behavior but also helps in managing the emotional dissonance as the workforces' disagreement with organizational actions, policies, and strategies which can be managed effectively when the organizations manage workforce emotions intelligently (Shojaei \& Siuki, 2014). Emotional dissonance not only affects workforces' behavior in undesirable manners (psychological detachment) but also affects the smooth functioning of the concerned organization (Rivkin, Diestel \& Schmidt, 2015). On one side, there exists a positive and significant relationship between emotional intelligence and innovative behavior but on the other side, when combined with exhaustion are likely to influence the organizational outcomes (Magnano, Santisi \& Platania, 2017). Emotional intelligence is therefore accommodative in managing innovative behavior and emotional dissonance due to its encouraging role in managing the emotions, abilities, and intellectual capabilities of workforces (Andrabi \& Rainayee, 2020). Therefore, this study aims to examine the role of emotional intelligence in predicting innovative behavior and emotional dissonance.

\section{Emotional Intelligence}

The emotion at workplaces is an important phenomenon that deals with the feelings and mindset with the notion that a peaceful mind paves the way toward the road of development and success. Emotional intelligence has significant standing in all spheres of life either domestic or professional as it helps in managing the brutal attitude towards calm behavior (Wong \& Law, 2002). The researchers categorized the intelligence into social and emotional dimensions wherein social intelligence denotes the interpersonal interaction of individuals in the society while emotional intelligence has been recognized in an organizational context that denotes the abilities of the organizations in managing the emotions at the workplace (Suliman \& AlShaikh, 2007). The emotions are the outcomes of feelings' expression in understanding and evaluating the different eventualities that are effective in making decisions over intellectual and emotional development (Dincer, Gencer, Orhan \& Sahinbas, 2011). Emotional intelligence is used to define emotional features likewise understanding and expressing emotions, adaptation, empathy, freedom, empowerment that helps in inspiring workforces to be innovative and creative (Andrabi \& Rainayee, 2020) in attaining organizational long-term objectives efficiently and effectively despite diverse conflicts and dissonance in between the workforces and organization. 


\section{Emotional Dissonance}

The recent changes in the working environment and technological advancement forced the organizations to take certain valuable measures and hard decisions to improve their quality and standards. However, some decisions are thus interactive for some workforces to adopt novel policies and practices and consequently show their emotional dissonance with these decisions (Dijk \& Brown, 2006). Emotional dissonance is the expressive disagreement of the workforces with the organizational decisions which culminates at different natures of conflicts between workforces and organization (Mishra \& Bhatnagar, 2010). These conflicts not only affect the working format and outcomes of the concerned organization but also affects the potential and wellbeing of the workforces (Szczygieł \& Bazińska, 2013). In this connection, the organizations are required to maintain the physical and facial expression of workforces for the smooth functioning of the organizational activities which can be affected undesirably by certain nature of psychological detachments (Rivkin, Diestel \& Schmidt, 2015). Thus, the emotional dissonance hinders supportive interaction between workforces and organization as creates emotional distancing which further leads to ineffective professional attitude and behavior (Simbula, Mazzetti \& Guglielmi, 2019). The emotional dissonance not only affects the emotional intelligence of the workforces but also affects the innovative work behavior undesirably.

\section{Innovative Work Behavior}

In the contemporary era, it is the basic responsibility of organizations to ensure creativity and innovation to achieve their desired standards and success. Without innovations, the organizations may not be able to attain the desired position in competitive environments as traditional ways are not enough to meet the desired standards (Getz \& Robinson, 2003). In this regard, the innovative work behavior of the workforces is critical for the organizations in ensuring their strong positions in the competitive scenario (Ivcevic, Brackett \& Mayer, 2007). The innovative behavior denotes the workforces' abilities towards the investigation of new chances and generation of innovative ideas which further helps in applying new knowledge, implementing change, and refining procedures to improve the performances in the organization (Dincer, Gencer, Orhan \& Sahinbas, 2011). Thus, innovative behavior comprehends a broader set of behaviors related to ideas generation, support creation, and effective application of innovative techniques to attain desired tasks (Shojaei \& Siuki, 2014). The innovative work behavior is critical in determining the emotional intelligence and also helps in managing the emotional dissonance in effective manners (Andrabi \& Rainayee, 2020). The innovative work behavior and emotional intelligence of workforces are also supportive and inspiring in managing emotional stress and exhaustion which are the outcomes of emotional dissonance at the workplace.

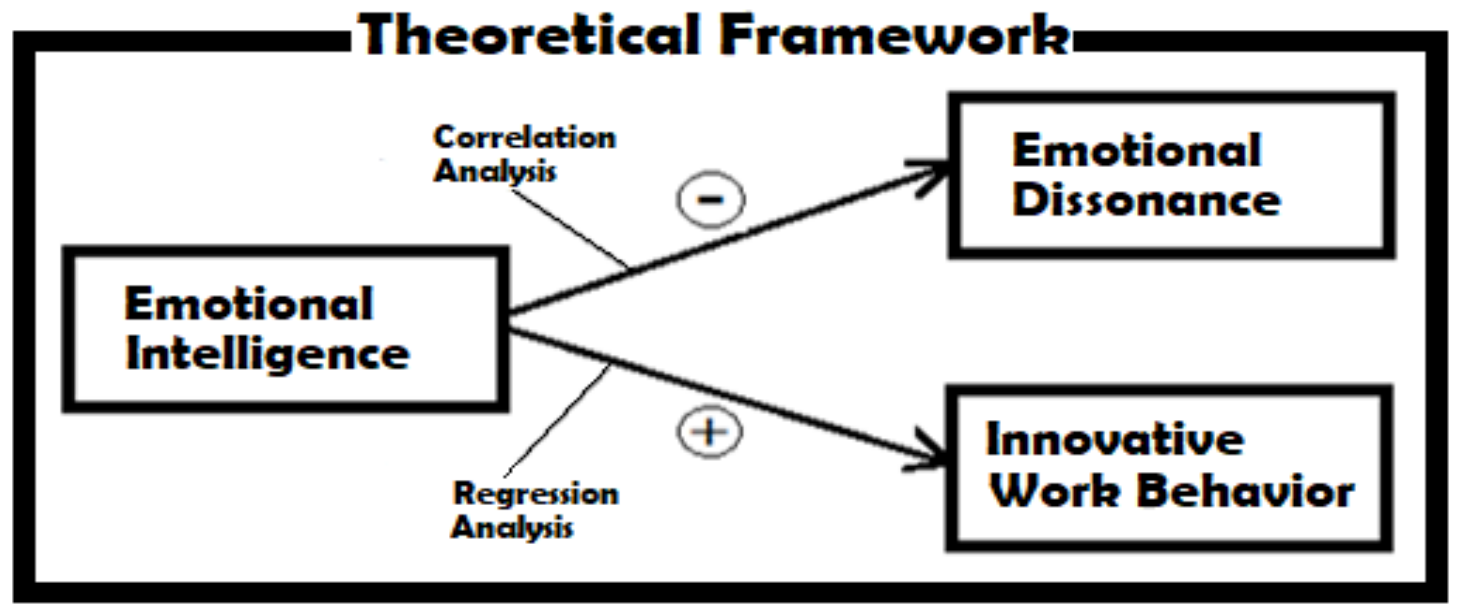

Figure 1: Theoretical Framework

Source: Authors' Own Work

\section{Hypotheses of Study}

$\checkmark$ There is a significant association between emotional intelligence, emotional dissonance, and innovative work behavior (hypothesis \# 1).

$\checkmark$ Emotional intelligence has a significant negative impact on the emotional dissonance of workforces (hypothesis \# 2).

$\checkmark$ To emotional intelligence has a significant positive impact on innovative work behavior (hypothesis \# 3). 


\section{RESEARCH METHODOLOGY}

The present study is based upon exploring certain existing realities in the native environment by collecting data applying different statistical tools to find answers to the research questions, therefore, positivism is the most befitting approach for conducting this study. The positivist philosophy follows the views that only accurate knowledge gained over observation and measurement is trustworthy. In the positivism approach, the researcher's role is limited to "data collection and interpretation" in an objective means. Similarly, to access the population of the study, the survey approach has been used. The population comprised of the workforces selected from southern region HEIs (4 universities) of KP, Pakistan. The sample (325) has been extracted from the population (1740) by using statistical formula (Yamani, 1967).

The primary data was collected through the questionnaire by applying the simple random technique while secondary data was collected through various online sources (articles). Total 325 questionnaires were distributed among which 290 were recollected (89\% response rate). The research concepts were measured through different statements related to research variables. The scales were adopted from previous research studies likewise for emotional intelligence, Wong and Law (2002)

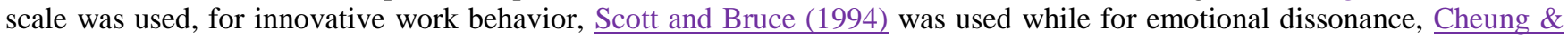
Tang (2007) scale has been utilized. The responses of the respondents were recorded through the 7-point Likert Scale. The secondary data was thus analyzed through the argumentation process while the primary data was analyzed through different tools like correlation and regression. The reliability of the instrument was done through Cronbach Alpha.

Table 1: Sample-Size Formula

\begin{tabular}{lll}
\hline $\mathbf{E}$ & $\mathbf{N}$ & Sample Size \\
\hline 0.05 & 1740 & 325 \\
\hline Formula & $\mathrm{n}=1740 /(1+1740(0.0025))$ & Distributed $=325$ \\
$\mathrm{n}=\mathrm{N} / 1+\mathrm{Ne}^{2}$ & $\mathrm{n}=325.23$ & Recollected $=290$ \\
\hline
\end{tabular}

Table 2: Reliability Statistics

\begin{tabular}{llll}
\hline SN & Research Variables & Items & Cronbach Alpha \\
\hline 1 & Emotional Intelligence & 10 & .861 \\
\hline 2 & Innovative Work Behavior & 10 & .789 \\
\hline 3 & Emotional Dissonance & 10 & .713 \\
\hline 5 & Overall Questionnaire & 30 & .884 \\
\hline
\end{tabular}

Table 3: Descriptive Statistics

\begin{tabular}{llllll}
\hline & $\mathrm{N}$ & Minimum & Maximum & Mean & SD \\
\hline Emotional Intelligence & 290 & 1.57 & 6.34 & 3.5376 & .89651 \\
\hline Innovative Work Behavior & 290 & 1.00 & 7.00 & 3.8685 & 1.11695 \\
\hline Emotional Dissonance & 290 & 1.43 & 6.92 & 4.8564 & 1.34853 \\
\hline Valid N (list-wise) & 290 & & & & \\
\hline
\end{tabular}

\section{DATA ANALYSIS}

The data has been analyzed through different tools to attain the desired objectives to find research questions' answers. The results of the study have been validated through existing research studies results to discuss the commonalities and differences and to make a clear position of the present study. The hypotheses were extracted from a theoretical framework about the relationships (association \& cause-\&-effect) among research variables and results have been presented in this section.

$\mathbf{H}_{1}$ : Association (emotional intelligence, emotional dissonance \& innovative work behavior).

Table 4: Correlation Analysis $\left(\mathrm{H}_{1}\right)$

\begin{tabular}{llll}
\hline & & Emotional Dissonance & Innovative Work Behavior \\
\hline \multirow{2}{*}{ Emotional Intelligence } & Pearson Correlation & $-.501^{* *}$ & $.469^{* *}$ \\
\cline { 2 - 4 } & Sig. (2-tailed) & .000 & .000 \\
\cline { 2 - 4 } & $\mathrm{N}$ & 290 & 290 \\
\hline
\end{tabular}

**. Correlation is significant at the 0.01 level (2-tailed).

The $\mathrm{H}_{1}$ was aimed to examine the association among the emotional intelligence, emotional dissonance, and innovative work behavior by using a correlation procedure. The results from correlation confirmed the existence of association wherein emotional intelligence positively and significantly associated with innovative work behavior $(\mathrm{R}=.469 \& \mathrm{P}$-values $=.000)$ of the workforces hailing from higher institutions of KP, Pakistan by analyzing the views of 290 workforces about the 
relationships between research variables. The results revealed that emotional intelligence is significantly but negatively correlated with emotional dissonance $(\mathrm{R}=-.501 \& \mathrm{P}$-values $=.000)$. Therefore, it is concluded that emotional intelligence has a positive relationship with innovative work behavior while a negative link with emotional dissonance. Consequently, from correlation results, the hypothesis about the association is thus accepted.

$\mathbf{H}_{2}$ : Impact (emotional intelligence on emotional dissonance).

Table 5: Regression Analysis (Model Summary)

\begin{tabular}{ccccccc}
\hline Model & $\mathbf{R}$ & $\mathbf{R}^{2}$ & Adjusted $\mathbf{R}^{2}$ & SEE & F & Sig. \\
\hline 1 & $.501 \mathrm{a}$ & .251 & .249 & .65830 & 96.675 & .000 \\
\hline
\end{tabular}

Table 5a: Regression Analysis (Coefficients)

\begin{tabular}{lllllll}
\hline \multirow{2}{*}{ Model } & \multicolumn{2}{l}{ Unstandardized Coefficients } & Standardized Coefficients & \multirow{2}{*}{ t } & \multirow{2}{*}{ Sig. } \\
\cline { 2 - 5 } & B & Std. Error & Beta & & \\
\hline \multirow{2}{*}{1} & (Constant) & 6.501 & .364 & & -9.883 & .000 \\
\cline { 2 - 5 } & Emotional Intelligence & -.597 & .061 & -.501 & -9.832 & .000 \\
\hline
\end{tabular}

a. Predictors: (Constant), Emotional Intelligence.

b. Dependent Variable: Emotional Dissonance.

The $\mathrm{H}_{2}$ was related to predicting emotional dissonance through emotional intelligence by using the regression procedure. The results show the $25.1 \%$ variance in emotional dissonance is due to emotional intelligence. In the coefficient of determination, emotional intelligence shows a significant impact on the emotional dissonance $(\beta=-.597 \& \mathrm{p}$-value $=.000)$ which shows that emotional intelligence is significantly but negatively determined by emotional intelligence. The main reason behind the undesirable relationship is the nature of these concepts likewise the intelligence and dissonance. However, the intellectual capabilities of workforces may help in changing the behavior of the workforces from disagreement to agreement. Thus, from the results, the hypothesis about cause-\&-effect is accepted.

$\mathbf{H}_{3}$ : Impact (emotional intelligence on innovative work behavior).

Table 6: Regression Analysis $\left(\mathrm{H}_{3}\right)$

\begin{tabular}{ccccccc}
\hline Model & $\mathbf{R}$ & $\mathbf{R}^{\mathbf{2}}$ & Adjusted $\mathbf{R}^{2}$ & $\mathbf{S E E}$ & $\mathbf{F}$ & Sig. \\
\hline 1 & $.469 \mathrm{a}$ & .336 & .333 & .45552 & 45.393 & $.000 \mathrm{~b}$ \\
\hline
\end{tabular}

Table 6a: Regression Analysis (Coefficients)

\begin{tabular}{lllllll}
\hline \multirow{2}{*}{ Model } & \multicolumn{2}{l}{ Unstandardized Coefficients } & Standardized Coefficients & \multirow{2}{*}{ t } & \multirow{2}{*}{ Sig. } \\
\cline { 2 - 5 } & B & Std. Error & Beta & & \\
\hline \multirow{2}{*}{1} & (Constant) & 2.660 & .252 & & 10.573 & .000 \\
\cline { 2 - 5 } & Emotional Intelligence & .283 & .042 & .369 & 6.737 & .000 \\
\hline
\end{tabular}

a. Predictors: (Constant), Emotional Intelligence.

b. Dependent Variable: Innovative Work Behavior.

The $\mathrm{H}_{3}$ was concerned with the predictability of innovative work behavior through emotional intelligence by using the regression procedure. The results of the summary table show that $33.6 \%$ variance occurs in innovative work behavior due to emotional intelligence. The coefficient of regression shows significant impact of emotional intelligence on innovative work behavior $(\beta=.283 \& \mathrm{p}$-value $=.000)$. The emotionally intelligent workforces are likely to have greater potential and innovativeness in presenting novel procedures and methods in attaining their assigned tasks which is the main reason for the significant impact of emotional intelligence on innovative work behavior. From the results, the third hypothesis about the cause-\&-effect relationship is thus accepted.

\section{DISCUSSIONS}

The institutions need competent, committed, and intelligent workforces to achieve their desired standing and success in the contemporary competitive environment. The disciplinary emotional expression is thus critical for the workforces to show their utmost potential and intelligence at the workplace (Boyatzis, Goleman \& Rhee, 2000). Emotional intelligence inspires the workforces to show their professional attitude on one side and also show their compassionate and caring behavior on the other side (Douglas, Frink \& Ferris, 2004). Emotional intelligence helps in encouraging innovative work behavior however, on the other hand, it helps in augmenting the emotional dissension of workforces leading to the psychological agreement 
(Suliman \& AlShaikh, 2007). Emotional intelligence not only helps in improving innovation but also helps in decisionmaking (Rahim \& Malik, 2010). In the educational context, emotional intelligence is critical for the workforces and institutions in numerous ways as it helps in understanding the values of each other while interacting at different levels in the institutional hierarchy (Dincer, Gencer, Orhan \& Sahinbas, 2011). In the present study, emotional intelligent shows significant association and positive influence on innovative work behavior (Cote \& Miners, 2006; Hasan \& Orhan, 2012; Jafri, Dem \& Choden, 2016; Andrabi \& Rainayee, 2020). These relationships have been validated through existing research studies.

Emotional intelligence and emotional dissonance have been widely researched in different contexts (Cheung \& Tang, 2012). Emotional intelligence helps in maintaining a balance between emotional discrepancies and working contexts which creates incongruence between feeling and action overwhelmed at emotional disagreement which leads to higher depression, lowered self-esteem, and disaffection toward given responsibilities (Kenworthy, Fay, Frame \& Petree, 2014). The emotional dissonance paves the way towards emotional exhaustion that may be effectively controlled through intellectual capabilities and emotional intelligence (Monica \& Molino, 2016). There exists diverse nature of relationships among emotional intelligence, emotional dissonance, and innovative work behavior as on one hand, emotional intelligence is positively related with innovative behavior but on the other hand, it has a blended relationship with emotional dissonance (Brackett, Mayer \& Warner, 2004; Mishra \& Bhatnagar, 2010; Cheung \& Tang, 2012; Magnano, Santisi \& Platania, 2017; Andrabi \& Rainayee, 2020). The literature also offered enough evidence about the connection between innovative behavior and emotional dissonance. Emotional dissonance is a dynamic issue that hampers the workforces' abilities to observe, understand, integrate, and manage their emotions in the concerned institution.

\section{CONCLUSION}

The study was aimed to examine relationships (association \& effect) between emotional intelligence, innovative work behavior, and emotional dissonance. The results revealed that emotional intelligence has a positive association and a significant impact on innovative work behavior. Emotional intelligence helps in boosting creativity and innovation as it encourages the workforces to be innovative and creative to some extent in achieving the assigned tasks. Similarly, emotional intelligence shows a negative association with emotional dissonance and the same nature of the relationship has been evidenced while examining the impact of emotional intelligence on emotional dissonance. The emotional dissonance is the workforces' disagreement with procedures and practices that they feel that these policies are not in line with the agreement between the employees and employees. The violation of these strategies leads the workforces towards emotional dissonance. The diverse nature of relationships has also been evidence between innovative behavior and emotional dissonance as psychological disagreement is likely to influence innovation and creativity in concerned institutions. Therefore, the study provides sufficient evidence about the relationships among the emotional intelligence, innovative work behavior, and emotional dissonance from the results of the current study and the results from the existing research studies to conclude comprehensively.

\section{LIMITATIONS OF STUDY}

1. The study is limited only to particular issues (emotional intelligence, emotional dissonance, and innovative work behavior) and particular context (higher education institutions) in developing countries like Pakistan.

2. The study is limited to a particular methodological approach along with particular tools and techniques to attain the particular objectives that may help provide a better solution to cater to the situation.

3. The sample size is kept at the level of convenience and not concerning the nature of the problem relating to a particular community. So, there are limitations to expanding the sample size.

\section{RECOMMENDATIONS}

1. Emotional intelligence is the key element that encourages the workforces to show their intellectual capabilities to achieve the assigned tasks more efficiently. Therefore, the institutions are required to arrange certain policies and practices to improve the skills and knowledge of workforces by developing their behavior and to make them emotionally intelligent.

2. The innovative work behavior is critical for the workforces which motivates them to think innovatively in attaining their assigned tasks. The institutions need to focus on certain programs that may help them in boosting the creativity and innovation in the institutions which further helps them in attaining the desired standards and ranking in the competitive environments.

3. Emotional dissonance is critical for the institutions as it marks the behavior of the workforces in adverse manners. The institutions are required to highlight the issues that cause the emotional disagreement of the workforces by taking suitable measures to cater to the situation and motivate them to perform the responsibilities effectively and wholeheartedly. 


\section{MANAGERIAL IMPLICATIONS}

$\checkmark$ Emotional intelligence is important for managers to take the right as well as suitable decisions. The management of the institutions are required to promote emotional intelligence among the workforces to attain the desired objectives more effectively.

$\checkmark$ The innovative behavior inspires the managers and workforces to think creatively and to act innovatively. The institutions are needed to comprehend the significance of innovation and ensure its applicability at all levels to produce more outcomes efficiently.

$\checkmark$ The emotional dissonance not only interrupts the workforces' behavior undesirably but also affects the institutional smooth functioning. The institutions are required to focus more on the elements that caused the disagreements of the workforces to attain desired standing and success.

$\checkmark$ The investigation of these variables in other contexts is direly needed to examine the commonalities and differences in results. Therefore, future researchers are thus required to add certain intervening variables to examine the significance of these concepts to extract more valuable information.

\section{AUTHORS' CONTRIBUTIONS}

This is a jointly conceptualized and written article. Dr. I.U. Khan is responsible for the idea and structure of the article and this was then planned collaboratively. Dr. M. Idris wrote the opening sections, and Dr. S. Noreen wrote the section on literature reviews and co-authored the conclusion with Dr. I.U. Khan and Dr. M. Idrees. Then, all authors gave feedback to each other overdrafts, proofreading, and edited before submission.

\section{REFERENCES}

1. Afsar, B., Cheema, S., \& Saeed, B. B. (2018). Do nurses display innovative work behavior when their values match with hospitals' values? European Journal of Innovation Management, 21(1), 157-171. https://doi.org/10.1108 /EJIM-01-2017-0007

2. Alam, F., Yifei, L., Raza, M., \& Khan, K. (2020). The impact of leader's emotional intelligence on employee organizational behavior: Mediating role of employee motivation. European Academic Research, VII, (10), 51275154.

3. Andrabi, N., \& Rainayee, R. (2020). Emotional Intelligence and Innovative Work Behavior: A Review. International Journal of Engineering and Management Research, 10 (4), 185-192. https://doi.org/10.31 033/ijemr.10.4.26

4. Basch, J., Fisher, D., Ashkanasy, M., Härtel, E., \& Zerbe, W. (2000). Affective events-emotions matrix: A classification of work events and associated emotions. In N. M. Ashkanasy (Ed.), Emotions in the workplace: Research, theory, and practice (pp. 36-48). Westport, CT: Quorum Books/Greenwood Publishing Group.

5. Boyatzis, R. E., Goleman, D., \& Rhee, K. (2000). Clustering competence in emotional intelligence: Insights from the Emotional Competence Inventory (ECI). In R. Bar-On \& J. A. Parker (Eds.), The Handbook of Emotional Intelligence: Theory, Development, Assessment, and Application at Home, School, and in the Workplace (pp. 343362). San Francisco: Jossey-Bass.

6. Brackett, M. A., Mayer, J. D., \& Warner, R. M. (2004). Emotional intelligence and its relation to everyday behaviour. Personality and Individual Differences, 36(6), 1387-1402. https://doi.org/10.1016/S0191$\underline{8869(03) 00236-8}$

7. Çakar, U., \& Yasemin, A. (2004). Changing Emotion in the Light of Modern Approaches-Intelligence Relation and Emotional Intelligence. DEÜ Journal of Social Sciences Institute, 6(3), 23-48.

8. Cheung, F. Y. L., \& Tang, C. S. K. (2007). The influence of emotional dissonance and resources at work on job burnout among Chinese human service employees. International Journal of Stress Management, 14(1), $72-87$. https://doi.org/10.1037/1072-5245.14.1.72

9. Cheung, F., \& Tang, C. (2012). The Effect of Emotional Dissonance and Emotional Intelligence on Work-Family Interference. Canadian Journal of Behavioral Sciences, 44 (1), 50 -58. https://doi.org/10.1037/a0025798

10. Cote, S., \& Miners, C., T. H. (2006). Emotional intelligence, cognitive intelligence, and job performance. Administrative Science Quarterly, 51(1), 1-28. https://doi.org/10.2189/asqu.51.1.1

11. Dijk, P. A., \& Brown, A. K. (2006). Emotional labour and negative job outcomes: An evaluation of the mediating role of emotional dissonance. Journal of Management and Organization, 12, 101-115. https://doi.org/10. 5172/jmo.2006.12.2.101

12. Dincer, H., Gencer, G., Orhan, N., \& Sahinbas, K. (2011). The significance of emotional intelligence on the innovative work behavior of managers as strategic decision-makers. Procedia-Social and Behavioral Sciences, 24, 909-919. https://doi.org/10.1016/j.sbspro.2011.09.052 
13. Douglas, C., Frink, D. D., \& Ferris, G. R. (2004). Emotional intelligence as a moderator of relationship between conscientiousness and performance. Journal of Leadership \& Organizational Studies, 10 (3), 2-13. https://doi.org/10.1177/107179190401000301

14. Getz, I., \& Robinson, A. G. (2003). Innovate or die: Is that a fact? Creativity and innovation management, 12(3), 130-136. https://doi.org/10.1111/1467-8691.00276

15. Hasan, D., \& Orhan, N. (2012). Relationship between emotional intelligence and innovative work behaviors in Turkish banking sector. International Journal of Finance \& Banking Studies, 1 (1), 21-28. https://doi.org/10.20525/ijfbs.v1i1.133

16. Ivcevic, Z., Brackett, M. A., \& Mayer, J. D. (2007). Emotional intelligence and emotional creativity. Journal of Personality, 75(2), 199-236. https://doi.org/10.1111/j.1467-6494.2007.00437.x

17. Jafri, M. H., Dem, C., \& Choden, S. (2016). Emotional intelligence and employee creativity: Moderating role of proactive personality and organizational climate. Business Perspectives and Research, 4(1), 54-66. https://doi.org/10.1177/2278533715605435

18. Kenworthy, J., Fay, C., Frame, M., \& Petree, R. (2014). A meta-analytic review of the relationship between emotional dissonance and emotional exhaustion. Journal of Applied Social Psychology, 44, 94-105. https://doi.org/10.1111/jasp.12211

19. Magnano, P., Santisi, G., \& Platania, S. (2017). Emotional intelligence as mediator between burnout and organizational outcomes. International Journal of Work Organizational Emotions, 8, 305-320. https://doi.org/10.1504/IJWOE.2017.089295

20. Mayer, J. D., Salovey, P., \& Caruso, D. R. (2008). Emotional intelligence: New ability or eclectic traits? American psychologist, 63(6), 503. https://doi.org/10.1037/0003-066X.63.6.503

21. Mishra, S. K., \& Bhatnagar, D. (2010). Linking Emotional Dissonance and Organizational Identification to Turnover Intention and Emotional Well-Being: A Study of Medical Representatives in India. Human Resource Management, 49 (3), 401-419. https://doi.org/10.1002/hrm.20362

22. Monica, E., \& Molino, F. (2016). Inbound Call Centers and Emotional Dissonance in the Job Demands - Resources Model. Work and Organizational Psychology, 7, 1-13. https://doi.org/10.3389/fpsyg.2016.01133

23. Naeem, H., Saif, M.I., \& Khalil, W. (2008). Emotional Intelligence and Its Impact on Service Quality Empirical Evidence from The Pakistani Banking Sector. International Business \& Economics Research Journal, 7, $12-55$. https://doi.org/10.19030/iber.v7i12.3313

24. Rahim, S. H., \& Malik, M. I. (2010). Emotional Intelligence \& Organizational Performance: (A Case Study of Banking Sector in Pakistan), International Journal of Business and Management, 5 (10). https://doi.org/10.5539/ijbm.v5n10p191

25. Rivkin, W., Diestel, S., \& Schmidt, K. (2015). Psychological detachment: A moderator in the relationship of selfcontrol demands and job strain. European Journal of Work Organizational Psychology, 24, 376-388. https://doi.org/10.1080/1359432X.2014.924926

26. Scott, S. G., \& Bruce, R. A. (1994). Determinants of Innovative Behavior: A Path Model of Individual Innovation in the Workplace. Academy of Management Journal, 38, 1442-65.

27. Shojaei, M., \& Siuki, M. (2014). A study of relationship between emotional intelligence and innovative work behavior of managers. Management Science Letters, 4(7), 1449-1454. https://doi.org/10.5267/j.msl.2014.6.021

28. Simbula, S., Mazzetti, G., \& Guglielmi, D. (2019). A Three-Wave Study on the Reciprocal Relationships between Emotional Dissonance, Need for Recovery, and Exhaustion. Sustainability 2019, 11, 5183, 2-16. https://doi.org/10.3390/su11195183

29. Suliman, A. M., \& AlShaikh, F. N. (2007). Emotional intelligence at work: Links to conflict and innovation. Employee Relations, 29(2), 208-220. https://doi.org/10.1108/01425450710720020

30. Szczygieł, D., \& Bazińska, R. (2013). Emotional intelligence as a moderator in the relationship between negative emotions and emotional exhaustion among employees in service sector occupations. Polish Psychology Bulletin, 44, 75-86. https://doi.org/10.2478/ppb-2013-0023

31. Thanesa, I., \& Yadav, I. (2019). Construction of Adapted Emotional Dissonance Scale for Individuals in Service Sector. International journal of scientific \& technology research, 8 (11), 1202-1207.

32. Wong, C. S. \& Law, K. S. (2002). The effects of leader and follower emotional intelligence on performance and attitude: An exploratory study. The Leadership Quarterly, 13(3), 243-274. https://doi.org/10.1016/S10489843(02)00099-1

33. Yamani, T. (1967). Statistics: An Introductory Analysis, 2nd Edition, New York: Harper and Row. 